\title{
Seismic shear distribution among interconnected cantilever walls of different lengths
}

\author{
Katrin Beyer ${ }^{1, *}$, Sabrina Simonini ${ }^{1}$, Raluca Constantin ${ }^{1}$ and Avigdor Rutenberg ${ }^{2}$ \\ ${ }^{1}$ École Polytechnique Fédérale de Lausanne (EPFL), Lausanne, Switzerland \\ ${ }^{2}$ Technion - Israel Institute of Technology, Haifa, Israel
}

\begin{abstract}
SUMMARY
Mid-rise to high-rise buildings in seismic areas are often braced by slender reinforced concrete (RC) walls, which are interconnected by RC floor diaphragms. In design, it is typically assumed that the lateral forces are distributed in proportion to the wall's elastic stiffness. Pushover analyses of systems comprising walls of different lengths have, however, shown that large compatibility forces can develop between them, which should be considered in design, but the analyses have also shown that the magnitude of the computed forces is very sensitive to the modelling assumptions. Using the results of a complex shell element model as benchmark, different simple hand-calculation methods and inelastic beam element models are assessed and improved to yield reliable estimates of the base shear distribution among the individual walls comprising the interconnected wall system. Copyright ( 2014 John Wiley \& Sons, Ltd.
\end{abstract}

Received 5 February 2013; Revised 10 December 2013; Accepted 18 December 2013

KEY WORDS: seismic analysis; cantilever walls; RC walls; equivalent frame models; base shear amplification

\section{INTRODUCTION}

Multi-storey reinforced concrete (RC) buildings in regions of moderate to high seismicity are frequently braced by slender RC walls. Such walls are expected to undergo inelastic deformations during a design level earthquake. In order to ensure that the walls form a stable plastic flexural mechanism with sufficient displacement ductility, they are typically designed using capacity design principles [1]. A key element of capacity design is the estimation of the design shear forces, which must account for all sources that can amplify the shear forces as obtained from the equivalent static lateral force procedure, which is the standard procedure in major codes dealing with the seismic design of regular structures. Several research groups have developed dynamic amplification factors for estimating the increase in global base shear demand on a shear wall system due to the amplified effect of higher vibration modes when the structure undergoes inelastic deformations. Such dynamic amplification factors are useful in design as they eliminate the need for inelastic time history analysis. A state-of-the-art report on dynamic shear amplification can be found in [2].

For design, not only the global base shear demand is of interest but also its distribution among the individual cantilever walls. In multi-storey structures comprising interconnected cantilever walls of different lengths, the base shear distribution is complex as it varies during different stages of loading: While all walls are responding in the elastic range, the lateral force distribution among interconnected walls is proportional to their relative lateral stiffness. When all walls have yielded, the base shear is distributed proportional to the moment capacity at the wall bases. Between these two stages, when some walls are elastic while others have already started to form a plastic hinge at

*Correspondence to: Katrin Beyer, École Polytechnique Fédérale de Lausanne (EPFL), Lausanne, Switzerland.

${ }^{\dagger}$ E-mail: katrin.beyer@epfl.ch 
their base, the base shear is neither distributed proportional to the elastic stiffness nor to wall strength. When some walls are elastic while others have yielded, the incremental lateral deformations of walls that are not interconnected would not be compatible at the floor levels. The incremental lateral deformations of a single wall that is still elastic would correspond to the deflected shape of an elastic wall fixed at the base while the incremental lateral deformations of a single wall that has already formed a plastic hinge at its base correspond to a rigid body rotation around the plastic hinge. The incremental lateral deformations of cantilever walls interconnected by floor diaphragms that are rigid in-plane have to be identical at floor levels. In order to make the incremental displacements of all walls identical, the floor diaphragms must transfer in-plane forces. These compatibility forces alter the base shear distribution among the walls while the total base shear of the system remains unaffected. Previous studies have shown that these compatibility forces tend to increase the base shear demand on the short walls and reduce it on the long walls [3-6]. This increase in base shear in the more slender walls of a cantilever wall system is only indirectly related to the dynamic amplification. The latter influences the height of the resultant of the horizontal inertia forces acting on the wall system, which in turn affects the forces transferred by the floor diaphragms. The shear redistribution in cantilever wall systems due to compatibility forces must be considered when analysing the system as it is not accounted for by codified dynamic amplification factors.

Typically, the inelastic behaviour of cantilever wall systems, which is not dominated by higher mode effects, is analysed using pushover analysis. During the design process of new structures, pushover analysis is not a standard tool and simpler models, which can be analysed by hand, are desirable. Such models for interconnected cantilever walls were proposed by Paulay and Restrepo [7] and Rutenberg and Nsieri [3, 4]. The two models represent limit cases concerning the effect of floor diaphragms on the base shear distribution between the walls. Section 3 presents the two models and outlines the underlying assumptions. Next, the results of these methods are compared to the pushover analysis results of different numerical models. The first numerical model is an advanced shell element model (SEM) with nonlinear material constitutive models for concrete and reinforcement (Section 4). The second and third numerical models are equivalent frame models and include distributed plasticity beam element (DPBM) and lumped plasticity beam element (LPBM), respectively (Section 5). The results of SEM are taken as benchmarks, and the results of the handcalculation methods, the LPBM and the DPBM are judged based on their agreement with SEM results. As all compatibility forces in statically indeterminate systems, their magnitude depends largely on the relative stiffness of the different elements. For this reason, the sensitivity of the analysis results to the modelling assumptions underlying the beam element models is investigated, and recommendations for modelling interconnected cantilever wall structures are formulated. The comparison of the different models is illustrated using an eight-storey cantilever wall system composed of two walls of different lengths (Section 2). In order to investigate the base shear distribution in different cantilever systems, a limited parametric study on cantilever wall systems with two walls of different lengths is carried out, in which the wall length ratio and the height of the resultant lateral force are varied (Section 6). The paper concludes with the findings of the parametric study and recommendations for the analysis of cantilever wall systems (Section 7).

In the following the term 'interconnected walls' refers to analyses in which equal lateral displacements are enforced on the walls at floor levels. The term 'single walls' is used to describe the behaviour of the walls when the effect of the interconnection by floor diaphragms is not considered.

\section{EXAMPLE STRUCTURE}

A simple structure is used to illustrate the differences between the analytical and numerical analysis approaches, which will be discussed in the following sections. The example structure is planar and has eight storeys. It is braced by two RC walls with rectangular cross sections, $6 \mathrm{~m}$ and $2 \mathrm{~m}$ long, respectively (Figure 1) and $0.2 \mathrm{~m}$ thick. The walls were designed according to Eurocode 8 [8]. The $\mathrm{RC}$ walls are interconnected at every floor level by a RC slab. In this study, the effect of gravity columns is not considered, that is, only the walls and the slabs spanning between the walls are 


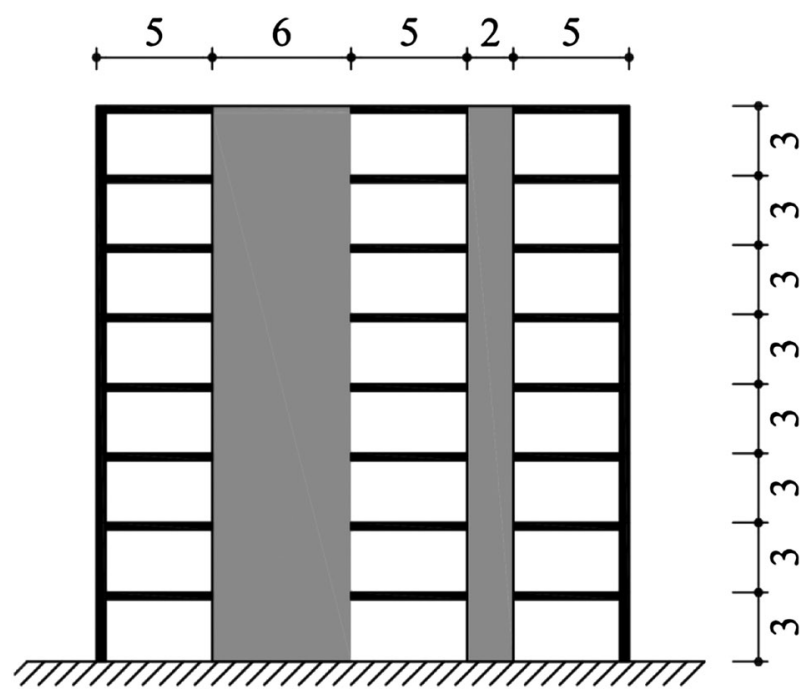

Figure 1. Geometry of the planar eight-storey model structure comprising two walls of different lengths (all dimensions in $m$ ).

modelled. Furthermore, all models presented in this paper do not account for the out-of-plane stiffness and strength of the slabs, which would affect the axial forces as well as the bending moments in the walls. The models are therefore only valid when the walls are spaced at a significant distance, so that the out-of-plane stiffness of the slab spanning between the walls becomes negligible.

\section{HAND-CALCULATION METHODS FOR THE ANALYSIS OF CANTILEVER WALL SYSTEMS}

This section presents two hand-calculation methods for the seismic analysis of cantilever wall systems. The first method by Paulay and Restrepo [7] assumes that the effect of floor diaphragms is negligible and that the walls can be treated as single walls subjected to the same top displacement. Rutenberg and Nsieri [3, 4], on the other hand, assume that the floor diaphragms are rigid in-plane and that the incremental displacement profile after yielding of the wall with the smallest yield displacements satisfies compatibility requirements.

The two hand-calculation methods require as input the force-deformation relationships of the two single walls. The yield curvature of a wall is estimated from the yield strain $\varepsilon_{s y}$ of the reinforcement, and the wall length $l_{w}[7,9]$

$$
\phi_{y} \approx \frac{2 \varepsilon_{s y}}{l_{w}}
$$

If all walls have the same height and cross-sectional shape and if for all walls the same type of reinforcement is used, the yield displacement of each wall can be expressed as proportionality constant times the inverse of the wall length:

$$
\Delta_{y} \approx C \frac{2 \varepsilon_{s y}}{l_{w}} H_{w}^{2} \propto \frac{1}{l_{w}}
$$

Hence, for similar moment profile shapes, the longer the wall, the smaller is its yield displacement. In a system of interconnected cantilever walls of different lengths, the longest wall will therefore yield first. As the approach by Rutenberg and Nsieri (Section 3.2) cannot account for any post-yield stiffness, the walls are modelled in this section by elastic-plastic force-displacement relationships. 


\subsection{Approach by Paulay and Restrepo}

Paulay and Restrepo [7] postulate that the force-deformation relationships of the walls in the interconnected cantilever wall system can be assumed to be identical to those of single walls, which were computed using the plastic hinge analysis approach as defined in Priestley et al. [9]. The system's force-deformation response can therefore be estimated as the sum of the force-deformation responses of the single walls (Figure 2(a)).

\subsection{Approach by Rutenberg and Nsieri}

Rutenberg and Nsieri (henceforth $R \& N$ ) developed a simple analytical approach for estimating the compatibility forces, which arise between two RC walls once the longer wall has yielded and the shorter is still elastic. They validated the analytical approach through nonlinear time history analysis of cantilever wall systems. In these analyses, the cantilever walls were modelled with one-component Giberson beam elements and a bilinear moment-curvature relationship [3]. R\&N formulated the approach in a general manner so that it can be applied to a system including any number of walls modelled by elastic-plastic force-displacement relationships. In this section, the method is presented for a system comprising two walls only, which are referred to as long wall and short wall. Up to yielding of the long wall, both walls behave in the same manner, and the system's base shear is distributed between the two walls in proportion to their stiffness. The system's base moment and base shear force after the onset of yielding of the long wall can increase by

$$
\begin{gathered}
\Delta M=M_{\text {short }, y}\left(1-\frac{\phi_{y, \text { long }}}{\phi_{y, \text { short }}}\right) \\
\Delta V=\frac{\Delta M}{h_{\text {eff }}}
\end{gathered}
$$

where $M_{\text {short,y }}$ is the yield moment of the short wall, $\phi_{\text {long,y }}$ and $\phi_{\text {short }, y}$ are the yield curvatures of the long and short wall, respectively, and $h_{\text {eff }}$ is the height of the resultant lateral force. Assuming infinite in-plane floor slab rigidity, neglecting shear deformation and any post-yield stiffness, the resulting base shear increments $\Delta V_{i}$ of the two walls after yielding of the long wall, can be estimated from

$$
\begin{gathered}
\Delta V_{\text {short }}=\frac{E I_{\text {short }}}{E I_{\text {long }}+E I_{\text {short }}}\left(\Delta V+\alpha \frac{\Delta M}{h_{s}} \cdot \frac{E I_{\text {long }}}{E I_{\text {short }}}\right) \\
\Delta V_{\text {long }}=\frac{E I_{\text {long }}}{E I_{\text {long }}+E I_{\text {short }}}\left(\Delta V-\alpha \frac{\Delta M}{h_{s}}\right)
\end{gathered}
$$
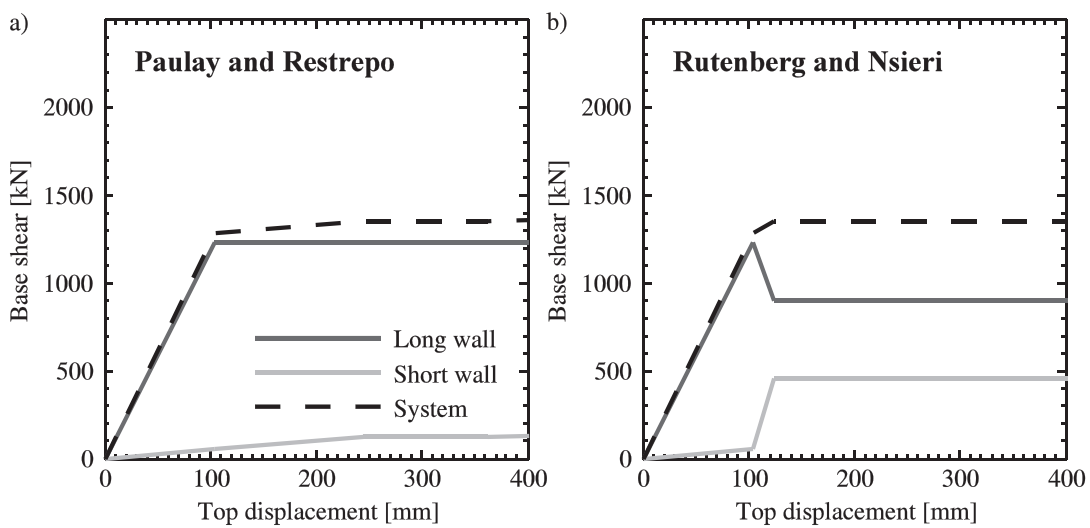

Figure 2. Force-deformation relationship of the long and short walls and of the system using two analytical models: (a) Paulay and Restrepo and (b) Rutenberg and Nsieri. 
where $E I_{\text {long }}$ is the flexural stiffness of the long wall, $E I_{\text {short }}$ the flexural stiffness of the short wall, $\Delta V$ the system's base shear increment, $\Delta M$ the system's base moment increment and $h_{s}$ the storey height. For walls having a uniform stiffness over the height, the factor $\alpha$ can be estimated as

$$
\alpha=3-\sqrt{3}=1.27
$$

The flexural stiffness of the walls corresponds to the effective stiffness at the onset of yielding:

$$
E I=\frac{M_{y}}{\phi_{y}}
$$

where $M_{y}$ is the nominal yield moment and $\phi_{y}$ the yield curvature of the wall section. As an example, the forces transmitted by the floor slabs, and the resulting base shear increments in a two-storey system due to a force $\Delta H$ acting at the top after the long wall has yielded is shown in Figure 3.

In Figure 3, the following additional assumptions were made:

- When compared to the short wall, the long wall is considered as infinitely rigid.

- Using the plastic hinge concept, the displacement field of the long wall after the onset of yielding can be described by a rigid body rotation about its base.

Rutenberg and Nsieri note that the underlying assumptions of the analytical model represent an oversimplification of the real wall behaviour because, for example, distributed plasticity and shear deformations will affect the actual behaviour. Herein R\&N's method is applied to the eight-storey example structure presented in Section 2, and the obtained base shear forces are plotted in Figure 2(b). Because of the compatibility forces arising after the onset of yielding of the long wall, the base shear of the long wall drops and that of the short wall increases. Hence, the peak base shear of the short wall of the interconnected cantilever wall system is therefore larger than that of the single short wall.

\subsection{Comparison of the results obtained with the two hand-calculation methods}

Figure 2 shows that the force-deformation relationship of the system is not affected by the assumptions concerning the compatibility forces transferred by the RC slabs, and therefore, both methods yield the same curve. The force-deformation relationships of the individual walls are, however, strongly affected by the assumptions concerning the compatibility forces transferred by the RC slabs. For design, the maximum base shears of the individual walls are of particular interest. While the peak value of the long wall is the same for the two models, the model by R\&N predicts for the short wall a maximum base shear that is in this case approximately $250 \%$ larger than the base shear predicted by Paulay and Restrepo, which corresponds to the base shear of the single wall.

As outlined in the introduction, the increase in the base shear of the short wall would have significant consequences on the seismic design of RC wall structures. However, before venturing on

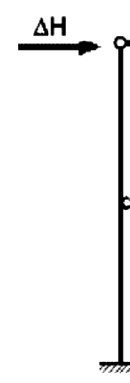

(a)

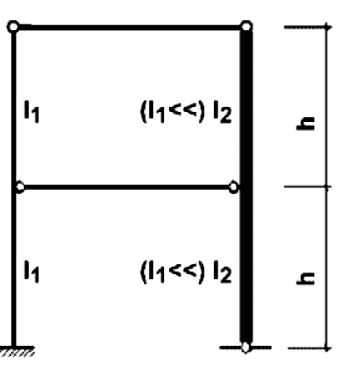

Wall 2

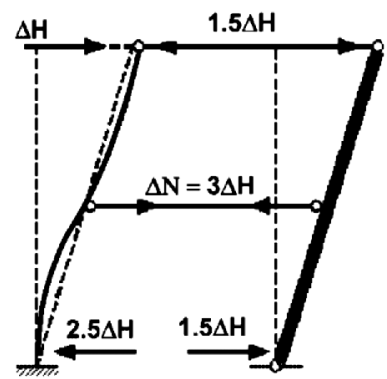

(b)

Figure 3. Two storey system: (a) Properties and loading and (b) assumed deflected shape and resulting floor forces and base shear forces (Rutenberg, 2004). 
a modification of design guidelines, we must determine whether the increase in base shear force is 'real', that is, whether it would also be observed in real structures if it could be measured, or whether it is mainly caused by modelling assumptions, which oversimplify reality. In order to obtain benchmark results in the absence of experimental evidence, it is necessary to analyse the example structure by means of a sophisticated nonlinear shell element model. This model is described in the following section.

\section{COMPARISON OF RESULTS: THE TWO HAND-CALCULATION METHODS VERSUS SHELL ELEMENT MODEL}

To obtain benchmark results, the example structure was analysed using the finite element program VecTor2 developed by Vecchio and his co-workers at the University of Toronto [10] for the analysis of planar 2D RC structures. The program is based on the Modified Compression Field Theory [11] and on the Disturbed Stress Field Theory [12]. The two walls were modelled using smeared longitudinal and transverse reinforcement. The walls were divided into boundary regions with higher longitudinal reinforcement ratios and web zones with lower longitudinal reinforcement ratios. In the boundary zones, the confining effect of stirrups and hoops was accounted for following the approach by Mander et al. [13]. The interconnection by the slabs was modelled by imposing on the two walls equal lateral displacement at the floor levels. For this purpose, the two walls were connected with truss elements having very large axial stiffness. The foundations of the two walls were modelled as rigid. The model geometry and mesh are shown in Figure 4(a). Lateral loading was applied through incremental lateral forces with equal values at every floor level.

Figure 4(b) compares the single wall results of the SEM with the results of the plastic hinge analysis, which approximates the former rather well. The results of the interconnected walls are compared to those of the two hand-calculation methods in Figure 5. The system's base shear is not sensitive to the modelling assumptions as it is not affected by the compatibility forces transferred by the floor diaphragms (Figure 5(c)). For the individual walls, the SEM results lie between the results obtained with the two hand-calculation methods (Figure 5(a) and (b)). As the analytical models differ only after the onset of yielding of the long wall, the peak base shear of the long wall is less sensitive to the modelling assumptions. For the short wall, on the other hand, the maximum base shear evaluated on the assumption that the compatibility forces do not affect the base shear demands [7] underestimates the base shear obtained with the SEM by $\sim 60 \%$. The model by R\&N [3, 4], however, overestimates the maximum base shear by $\sim 40 \%$. Overestimating base shear demand is safe from a designer's point of view, but a more accurate estimate might be needed for assessment purposes. Such an estimate is proposed in Section 6.

a)

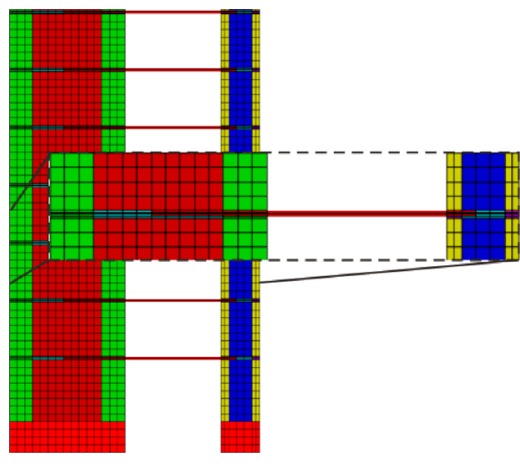

b)

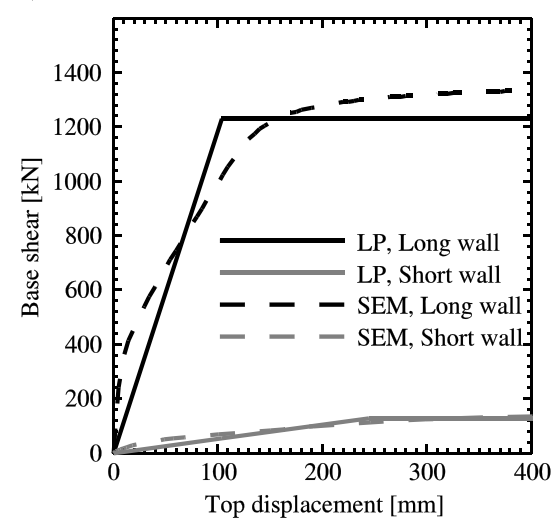

Figure 4. (a) Shell element modelling of the interconnected cantilever wall system. (b) Force-deformation relationships of the single walls: Comparison of results. 

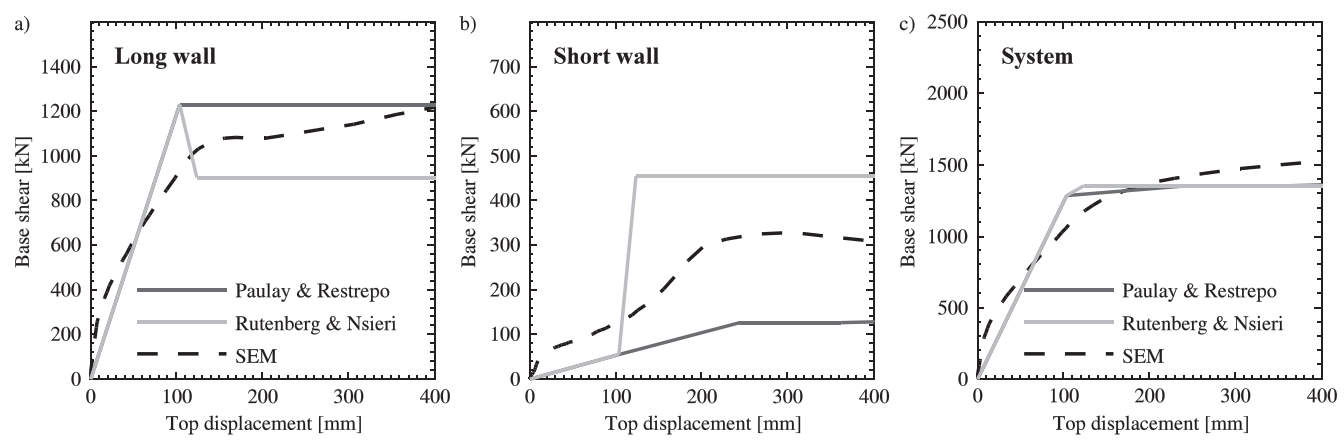

Figure 5. Force-deformation relationships of the interconnected cantilever walls and of the entire system: comparison of shell SEM versus the two analytical models.

\section{EQUIVALENT FRAME PUSHOVER RESULTS FOR INTERCONNECTED WALLS AND THEIR SENSITIVITY TO MODELLING ASSUMPTIONS}

The setting up of a SEM of a cantilever wall system requires some expertise and-although computational power increases continuously - the computational costs are still burdensome, in particular, when an iterative design procedure requires the analysis of several models. For design and assessment purposes, equivalent frame models are therefore frequently used for the inelastic analysis of such buildings. Equivalent frame models have been developed for a large range of structural systems, for example, such as RC core walls [14] and RC frames with masonry infills (e.g. [15]), and therefore can easily be combined when mixed structural systems are analysed. The purpose of this section is to evaluate the performance of different equivalent frame models of the example structure presented in Section 2 by benchmarking their results against the results of the SEM (Section 4). The models are compared with respect to the base shear distribution between the long and the short wall as well as to the total system's response. The comparison is based on monotonic pushover analyses using equal lateral forces at every floor level.

In Section 5.1, two models with lumped plasticity and distributed plasticity beam elements, respectively, are compared. The two models reflect the most commonly applied modelling assumptions for such structures. The analysis results of these two models are then benchmarked against the shell element results. Section 5.2 addresses the effect of shear-flexure interaction on shear flexibility. In the two following sections, the sensitivity of the results of the DPBM and the LPBM to refinements with respect to (wrt) the shear flexibility of the beam elements and for the LPBM, also wrt the element discretization and the shape of the backbone curve are investigated (Sections 5.3 and 5.4). Recommendations for modelling of cantilever wall systems by means of equivalent frame models are formulated in Section 5.5. Section 5.6 compares the cyclic response using DPBM and LPBM with their SEM counterpart.

In all analyses, the floor elements are modelled as horizontal rigid links having an infinite axial stiffness and therefore impose equal horizontal displacements on the two walls. The out-of-plane stiffness of the slabs is neglected. Evidently, this represents an oversimplification of the real structural behaviour where the floors have a limited in-of-plane and out-of-plane stiffness and strength. However, as the objective of the paper is to discuss the effect of the wall deformations on the compatibility forces transmitted by the floor diaphragms, modelling the floors as infinitely rigid in-plane and infinitely flexible out-of-plane allows eliminating all parameters related to the slab stiffness. Note, however, that in-plane floor flexibility is likely to lower the compatibility forces to some extent, but preliminary studies suggest that this effect is only minor [4-6]. All beam element models were analysed using the finite element programme Seismostruct [16], which includes in its element library a large range of elements and hysteresis rules, including links of zero length. Note, however, that it cannot directly model distributed shear flexibility in beam elements. 


\subsection{Sensitivity to beam element formulation: lumped plasticity versus distributed plasticity beam element model}

This section investigates the sensitivity of the base shear to the element formulation of the beam elements representing the wall sections. Two types of beam element models are considered a DPBM and an LPBM. Both models represent very common modelling assumptions for the analysis of interconnected slender cantilever wall systems. For such systems, it is often assumed that shear flexibility is negligible and only flexural flexibility of the wall elements is accounted for. The LPBM consists of elastic beam elements and inelastic moment-rotation springs representing plastic hinges at the wall base (Figure 6(a)). These plastic hinges were assigned bilinear moment-rotation relationships in order to match the results from section analysis.

The chosen distributed plasticity beam element is a displacement-based DPBM with fibre sections. As the curvature distribution over the length of the element is linear [17], more than one element per storey is required to capture the nonlinear curvature distribution when the wall is responding in the inelastic range. In the model of the example structure, two elements per storey are used. Yazgan and Dazio [18] recommend using element length equal to plastic hinge length $L_{p}$. For the long wall, the resulting half storey height corresponds to $L_{p}=1.48 \mathrm{~m}$ (per [9]). For the short wall, the element length of $1.50 \mathrm{~m}$ is somewhat larger than $L_{p}(=0.88 \mathrm{~m})$ but the approximation is still satisfactory.

Figure 6 shows the force-deformation relationships of the two models when each of the two walls is analysed as a single wall, that is, when the interconnection by the slabs is omitted. The bilinear curve of the LPBM approximates the force-deformation curves of the DPBM well when the walls are analysed as single walls. Figure 7 shows the results for the interconnected wall system and compares the results of the beam element models to those of the SEM. For the interconnected walls, the resulting base shears of the two models differ considerably. On the other hand, the system's response is not sensitive to the choice of beam element. The comparison with the SEM results shows that the model with distributed plasticity elements approximates the response of the SEM much better than the LPBM. The LPBM as applied here, that is, a single hinge at the wall base, overestimates the compatibility forces transferred as horizontal forces by the links, and therefore, the base shear distribution between the long and short wall is not well estimated after the onset of yielding of the long wall. This, however, does not affect the system's response. Hence, this basic LPBM seems suitable for estimating the system's response but may lead to unrealistic results concerning the internal force distribution in a statically indeterminate system such as interconnected walls, because the force distribution is very sensitive to assumed member stiffness. Improvements of LPBM by using more sophisticated moment-rotation relationships and adding another hinge in the first storey walls are addressed in Section 5.4.

a)

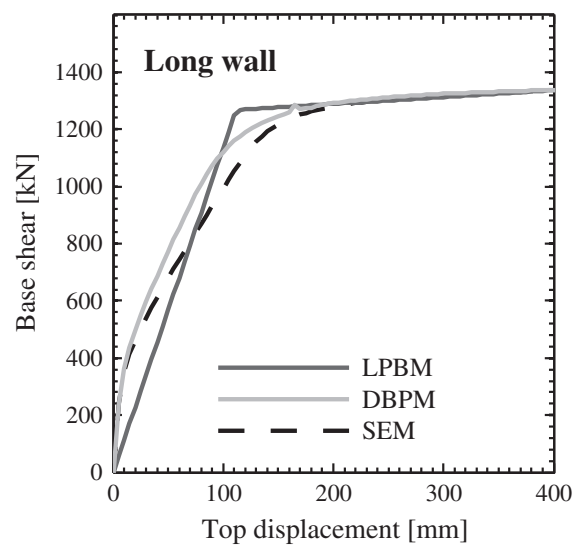

b)

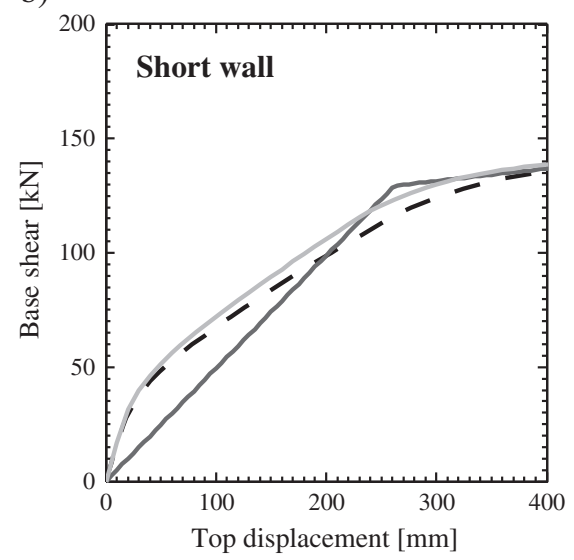

Figure 6. Force-deformation relationships of the single walls: comparison of lumped plasticity beam element (LPBM), distributed plasticity beam element (DPBM) and SEM results. 
a)

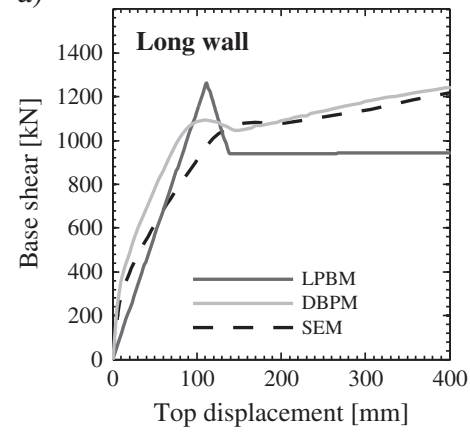

b)

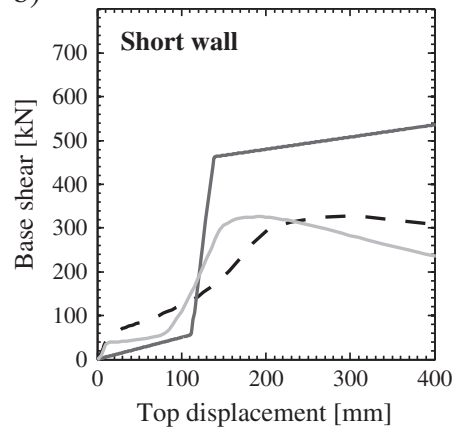

c)

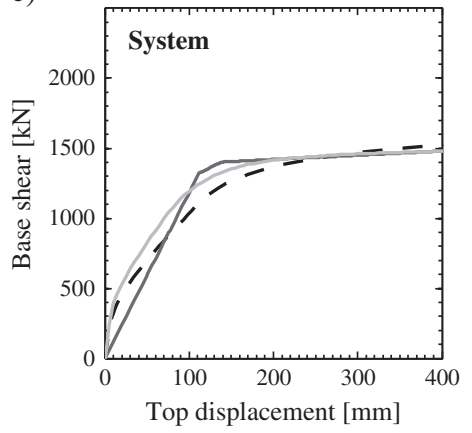

Figure 7. Force-deformation relationships of the interconnected cantilever walls and the entire system: comparison of lumped plasticity beam element (LPBM), distributed plasticity beam element (DPBM) and SEM results.

The results obtained with the LPBM correspond very well to the analytical results by R\&N (Figure 5). The two models agree quite well wrt the shear force distribution between the two walls after the onset of yielding of the long wall. This is to be expected as the $\mathrm{R} \& \mathrm{~N}$ model is also based on the assumption of concentrated plasticity at the wall base, and both models neglect the influence of shear flexibility. Note, however, that the R\&N model cannot account for post-yield stiffness while post-yield stiffness was considered in the LPBM.

\subsection{Modelling the shear flexibility in beam element models of wall structures}

Sections 5.3 and 5.4 show that the predictions of both DPBM and LPBM can be significantly improved if shear flexibility of the walls is included in the model. This section discusses the challenges related to modelling shear flexibility and proposes a simple approach for estimating the shear flexibility.

In routine analysis, it is often assumed that shear stiffness is proportional to $G A_{s}$ where $G=$ shear modulus and $A_{s}=$ shear area $\left(\approx 0.85 A_{\text {gross }}\right)$. In RC members responding in the inelastic range, the flexural and shear deformations are strongly coupled, and $G A_{s}$ may grossly underestimate shear deformations. For capacitydesigned RC walls, experimental results from quasi-static cyclic tests have shown that the ratio of shear to flexural deformations remains approximately constant over the entire ductility range [19]. This is contrary to the common assumption that shear deformations are proportional to the shear forces. Current standard beam element formulations do not allow capturing the coupling between flexural and shear flexibility correctly, and crude approximations, which consider flexural and shear deformations as independent quantities, are necessary. As noted, Seismostruct cannot directly model distributed shear stiffness. It is approximated herein by means of an elastic shear spring at storey midheight, and the resulting concentrated deformation is then smeared along the storey height. For the sake of simplicity, all storeys are assigned the same shear stiffness. The stiffness of the spring is constant throughout the analysis. Hence, the coupling of shear and flexural stiffness is not actually modelled but is accounted for by computing the shear flexibility according to [19] at one particular displacement demand rather than on the basis of the gross sectional shear stiffness $G A_{s}$. As compatibility forces are largest at the onset of the short wall yielding, it is recommended to compute the shear flexibilities corresponding to $\mu_{\Delta}=1$. The ratio of shear to flexural displacement $\Delta_{s} / \Delta_{f}$ is estimated from Beyer $e t$ al. [19] as

$$
\frac{\Delta_{s}}{\Delta_{f}}=1.5 \frac{\varepsilon_{m}}{\phi_{y} \cdot \tan \beta \cdot h_{e f f}}
$$

where $\varepsilon_{m}$ is the mean axial strain of the section at nominal yield, $\phi_{y}$ the nominal yield curvature, $\beta$ the cracking angle and $h_{\text {eff }}$ the effective height of the wall. The cracking angle was estimated from Collins and Mitchell [20]:

$$
\tan \beta=\frac{j d}{V_{n}}\left(f_{l} b_{w}+\frac{A_{s w} f_{y w}}{s}\right) \leqslant 90^{\circ}
$$


where $j d$ is the lever arm between the compression and tensile resultants at nominal yield, $V_{n}$ is the nominal yield force, $f_{l}$ the tensile strength orthogonal to the crack, $b_{w}$ the wall width, $A_{s w}, f_{y w}$ and $s$ are the area, yield strength and spacing of the shear reinforcement, respectively. The resulting ratios of shear to flexural deformation for the long and short wall were 0.10 and 0.04 , respectively. As outlined earlier, the shear stiffness was assumed as constant over the height of the wall. Assuming also a constant lateral force distribution over the height of the wall, the stiffness of the shear spring representing the shear flexibility of every storey of the eight storey walls can be estimated as

$$
\mathrm{k}_{\mathrm{s}}=\frac{\sum_{\mathrm{i}=1}^{8} \mathrm{~V}_{\mathrm{i}}}{\Delta_{\mathrm{s}}}=\frac{4.5 \mathrm{~V}_{\mathrm{n}}}{\Delta_{\mathrm{s}}}
$$

where $V_{i}$ is the storey shear force and $\Delta_{s}$ is the shear displacement at $\mu_{\Delta}=1$ and $V_{n}$ is the corresponding base shear. The distributed stiffness is then given by

$$
G_{e f f} A_{s}=k_{s} h_{s}
$$

\subsection{Improving the performance of the distributed plasticity beam model}

While the DPBM introduced in Section 5.1 approximates the response of the SEM much better than the LPBM, the redistribution of shear forces from the long to the short wall after the onset of yielding of the long wall is still overestimated when compared to the SEM. The DPBM in Section 5.1 did not account for shear flexibility. This section investigates the sensitivity of the base shear distribution between the long and the short wall to the shear flexibility of the walls.

Figure 8 shows the comparison of the DPBM with and without shear flexibility to the shell element model. Including shear flexibility in the beam model improves the match between it and the SEM regarding the redistribution of shear forces after the onset of yielding of the long wall. Figures 9 and 10 show that the two models agree quite well regarding the curvature profiles but less so regarding the distribution of shear deformations over the height of the walls. Note that Figure 10 shows both the stepped shear deformation per Equation (11a) and the continuous one per Equation (11b). The plots show the deformations for a top displacement of $190 \mathrm{~mm}$, approximately corresponding to the top displacement where the base shear of the short wall attains the maximum value.

For the short wall, matching the curvature distribution over the first storey height could further be improved if the length of the elements for the storey were reduced to that of the plastic hinge [18]. Force-based elements [21] provide approximately correct strain distributions only if flexural cracks are present. For RC walls, however, the inclined flexural-shear cracks lead to a spread of plasticity, for which force-based elements cannot account [18]. For this reason, displacement-based elements are preferred when modelling RC walls as the spread of inelasticity can then be controlled via element length.
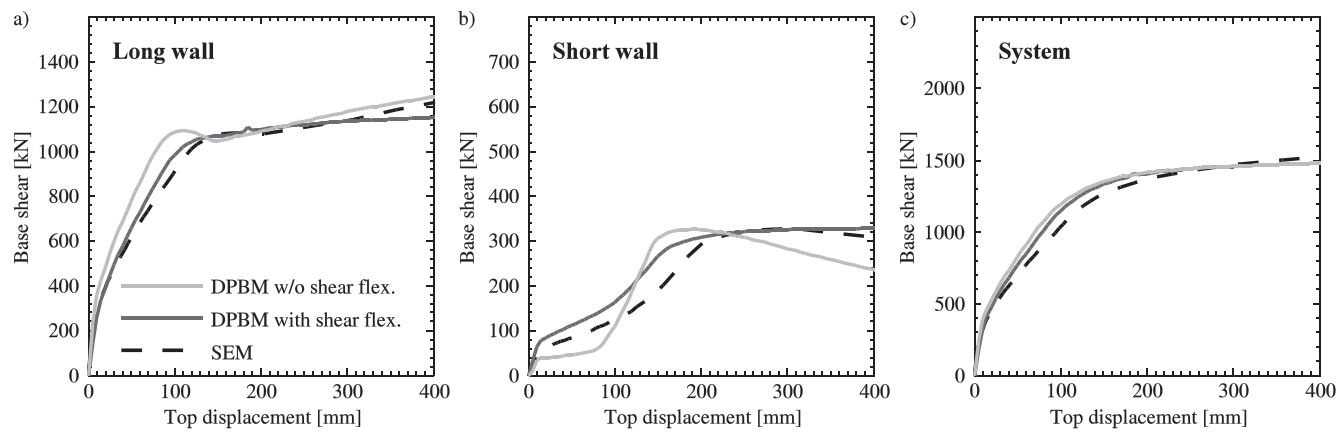

Figure 8. Force-deformation relationships of the interconnected cantilever walls and the entire system: influence of shear flexibility on distributed plasticity beam element (DPBM) results. 

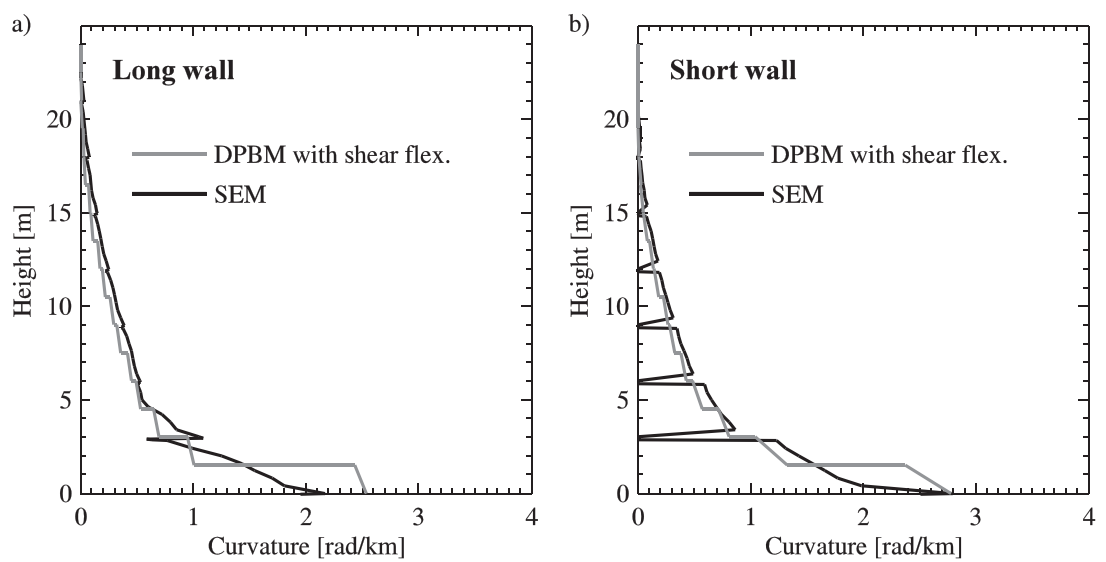

Figure 9. Curvature distribution over the height of the walls at top displacement of $190 \mathrm{~mm}$ : comparison of distributed plasticity beam element (DPBM) with shear flexibility and SEM.
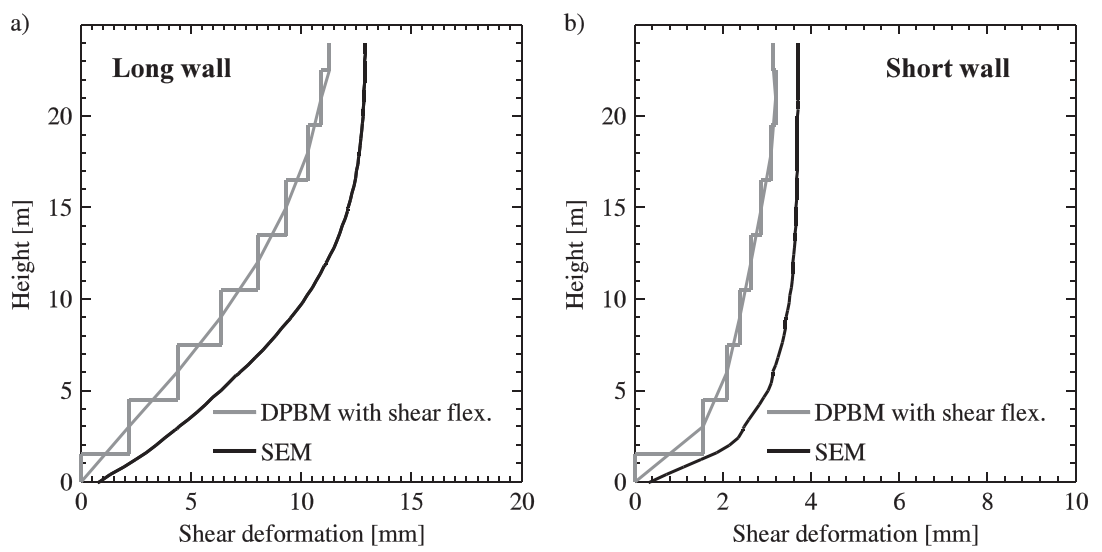

Figure 10. Shear deformation distribution over the height of the walls at a top displacement of $190 \mathrm{~mm}$ : comparison of distributed plasticity beam element (DPBM) with shear flexibility and SEM. Stepped lines per Equation (11a), continuous lines per Equation (11b).

For design, not only the base shear demand but also its distribution over the wall height is required. Figure 11 shows that the DPBM captures the shear force distribution obtained from the SEM very well. The results show that the compatibility forces affect only the shear forces of the lowest two storeys. For the short wall, the shear forces of the bottom quarter of the wall height need to be modified to account for the amplification due to the compatibility forces, while for the long wall neglecting the effect of the compatibility forces will be conservative.

\subsection{Improving the performance of the lumped plasticity beam element model}

The performance of the LPBM presented in Section 5.1 is not satisfactory when the base shear distribution between the different walls is of interest; only the total system base shear is estimated correctly. The objective of this section is to investigate whether the performance of the LPBM can be improved: (i) by using more sophisticated moment-rotation relationships; (ii) by adding another potential plastic hinge in the first storey walls in order to allow for inelastic deformation redistribution over the height of the walls; (iii) by introducing shear flexibility to the elements; and (iv) finally by combining all the aforementioned effects. In addition, the combined effect is compared to that of the bilinear model considering shear deformation.

The SEM moment-rotation relationship is far from linear along the whole range of interest. In order to investigate the influence of the shape of the moment-rotation relationship on the base shear 
a)

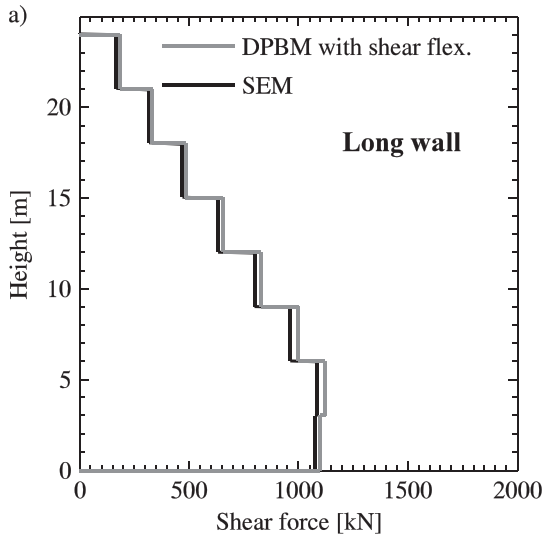

b)

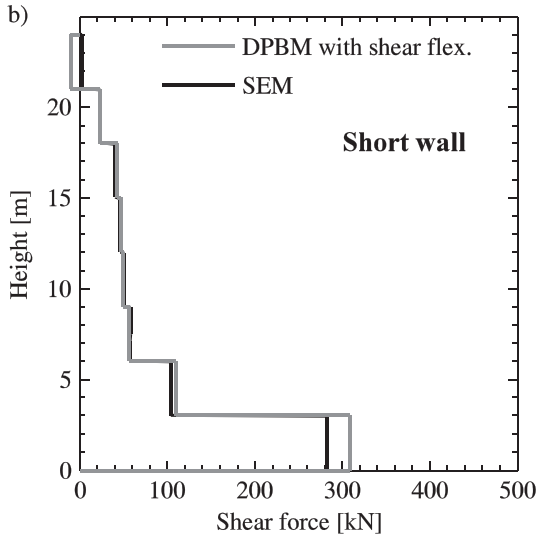

Figure 11. Shear force distribution over the height of the walls at top displacement of $190 \mathrm{~mm}$ : comparison of distributed plasticity beam element (DPBM) with shear flexibility and SEM.

distribution in the interconnected wall system, the bilinear curve describing the moment-rotation relationship was replaced by the rounded curve defined by Ramberg-Osgood (e.g., [22]), which features a gradual decrease in stiffness between the elastic and plastic behaviour. Ramberg-Osgood (R-O) is not considered to be suitable for modelling RC structures, but this was the only rounded curve model available to the authors in Seismostruct. The parameters of the R-O model were determined to best approximate the moment-curvature relationship obtained from a fibre section analysis. The plastic curvature was transformed into a rotation by multiplying it with the plastic hinge length of the wall. Note that the sharpness of the transition from the elastic to the plastic branch depends strongly on the distribution of the longitudinal reinforcement along the section: if the longitudinal reinforcement is concentrated at the edges or in boundary elements, the transition is more abrupt; otherwise, the transition is smoother. However, R-O cannot model the transition sharpness and hence is unable to predict the effect of steel concentration on the shear distribution among the walls. Figure 12 compares the results of the two LPBMs to the SEM. It demonstrates that the peak shear force obtained for the short wall is very sensitive to the shape of the moment-rotation relationship assigned to the LPBM but affects to a lesser extent the peak base shear in the long wall. The effects of added plastic hinges along the first storey height and added shear flexibility on the force-deformation relationships are demonstrated subsequently.

The lumped plasticity beam elements were originally developed for frame analysis, for which the assumption of localised inelastic deformations in columns and beams at their extremities holds reasonably well. For walls, however, the hinge length is on the order of the storey height; hence, concentration of inelastic deformations in a single plastic hinge at the wall base does not allow capturing correctly the deformation behaviour at the first storey. The deformation of the first storey controls the compatibility forces transferred therein, which to a large extent account for the increase
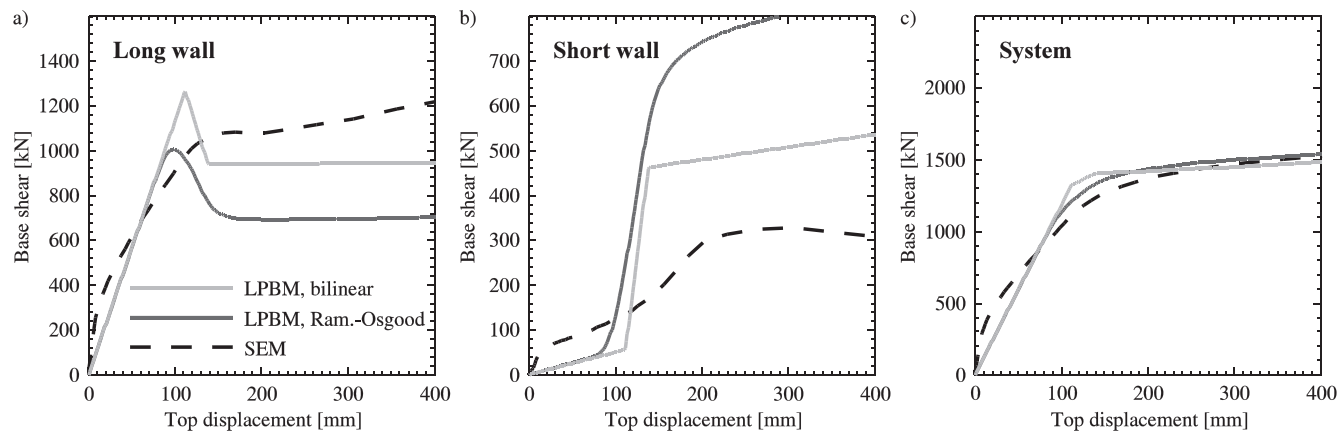

Figure 12. Force-deformation relationships of the interconnected cantilever walls and the entire system: comparison of lumped plasticity beam elements (LPBMs) with two hysteresis rules to SEM. 
in the base shear demand on the short wall relative to single walls. To allow for more realistic spread of plasticity over the height of the first storey, a second plastic hinge is introduced at midheight.

Figure 13 compares the two models. It shows that introducing additional potential plastic hinges over the height of the first storey did not have a significant influence on the peak base shear in the long wall but it affects the change in base shear after yielding of the long wall; the reason being that the peak base shear in the long wall occurs at the onset of its yielding, that is, before further plastic hinges form up the wall height. The second plastic hinge in the long wall starts to form at a top displacement of $150 \mathrm{~mm}$. Once this plastic hinge forms, the compatibility forces transferred by the floor diaphragms fall, and as a consequence, the base shear in the long wall increases, and the base shear in the short wall is reduced.

The key to improving the LPBM is the introduction of shear flexibility to the walls. As for the DPBM, the shear flexibility of the walls is included in the R-O model by means of shear springs at every storey midheight. The stiffness assigned to the shear springs is that given in Section 5.2. Figure 14 shows that including shear flexibility in the LPBM with two plastic hinges results in more satisfactory match with the shell element results.

Similar observations can be made for the bilinear LPBM: including shear flexibility in the bilinear hinge, LPBM has a significant influence on the peak shear forces of the two walls. Comparison with the SEM results shows that a simple LPBM model with only one plastic hinge per wall yields reasonable estimates of the base shear distribution (Figure 15). On the other hand, including an additional plastic hinge at first storey midheight does not influence the peak base shear in the long wall. The second plastic hinge in the long wall forms only after the yielding of the short wall and that at a very large displacement. As a result, this second plastic hinge has practically no effect on the peak shear force of the short wall (not shown). Note that comparing Figure 15 to Figure 13 suggests that the choice of the moment-rotation relationship becomes less important when shear flexibility is added to the model.
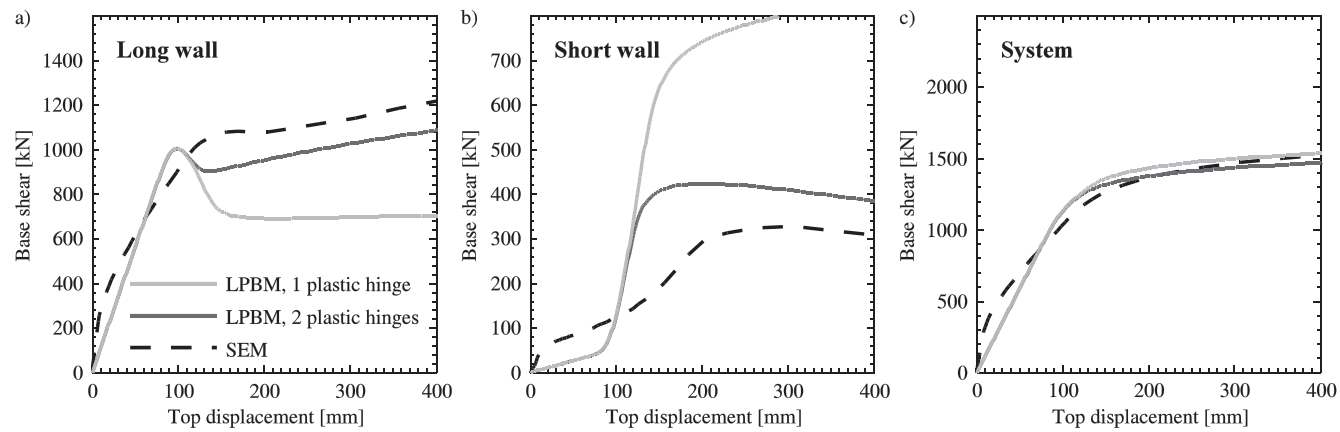

Figure 13. Force-deformation relationships of the interconnected walls and the entire system: comparison of Ramberg-Osgood lumped plasticity beam elements (LPBMs) with one and two plastic hinges per wall to SEM.
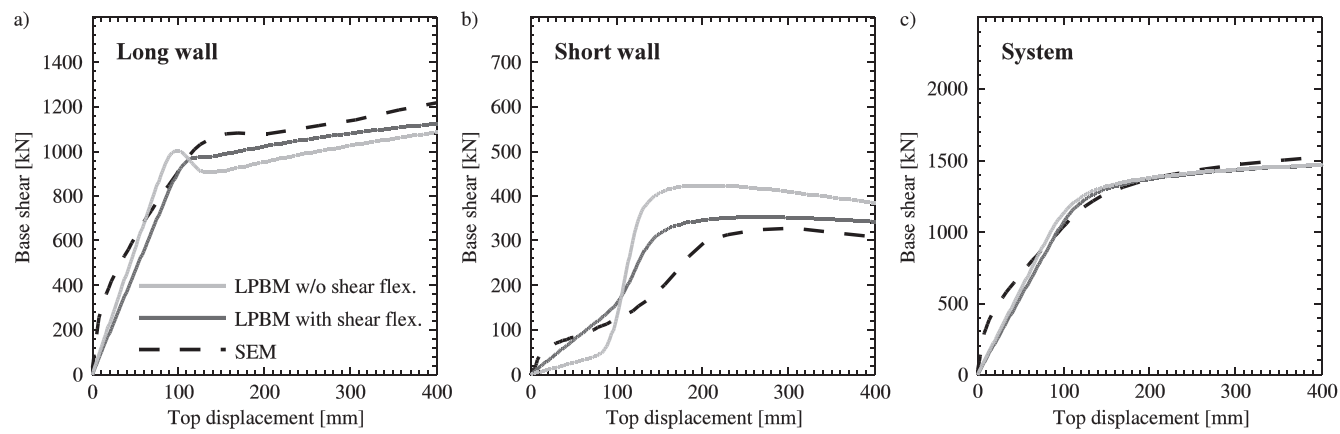

Figure 14. Force-deformation relationships of the interconnected walls and the entire system: effect of accounting for shear flexibility in Ramberg-Osgood lumped plasticity beam element (LPBM) (2 plastic hinges per wall). 

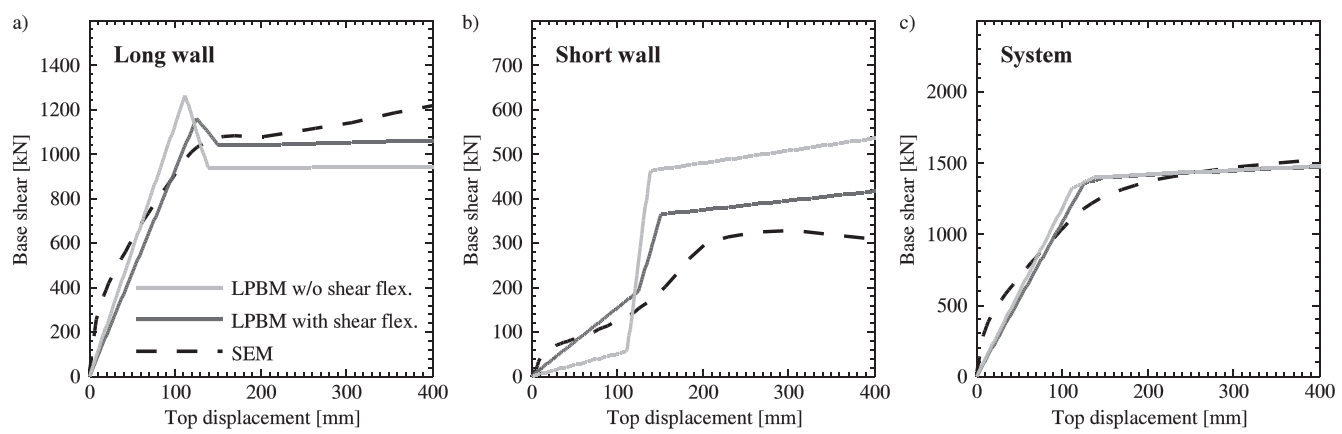

Figure 15. Force-deformation relationships of the interconnected walls and the entire system: effect of accounting for shear flexibility in lumped plasticity beam element (LPBM) with bilinear hysteresis (1 plastic hinge per wall).

\subsection{Modelling recommendations for cantilever wall systems}

When equivalent frame models are used to estimate the distribution of the base shear force in interconnected cantilever walls, particular attention needs to be paid to the modelling assumptions. The internal force distribution in statically indeterminate systems such as interconnected cantilever walls is affected by compatibility forces. These largely depend on the relative stiffness of the different elements. When computing the internal force distribution in such systems, it is therefore important to use good approximations for the element stiffness. This section summarises recommendations for modelling interconnected cantilever walls by equivalent frame models.

The analyses presented in this paper have shown that the base shear distribution is particularly sensitive to the modelling assumptions regarding shear flexibility of the wall and element discretization. All beam models should account for shear flexibility. Standard beam elements, which are implemented in structural engineering programmes (lumped plasticity beam elements and distributed plasticity beam elements), cannot account for shear-flexure interaction; hence, the shear stiffness cannot be updated during the analysis, and a fixed shear flexibility needs to be specified, which can only be representative of the shear flexibility at one particular displacement demand. As the compatibility forces are largest at the onset of yielding of the shorter wall, it is recommended computing the shear flexibilities corresponding to $\mu_{\Delta}=1$. Equations for estimating the shear flexibility have been presented in Beyer et al. [19] and are summarised in Section 5.2. In Seismostruct [16], the shear flexibility is included in the beam element models by means of a shear spring at midheight of each storey. Therefore, every wall should be modelled by two beam elements per storey. For equivalent frame models with displacement-based distributed plasticity beam elements, having linear curvature profiles along the beam length, this will usually also lead to good approximation of the curvature demand at the wall base. For short walls, a closer discretization might be considered with element length reduced to the plastic hinge length [18].

For beam elements with lumped plasticity modelled using R-O, the introduction of a second plastic hinge at midheight of the first storey helps capturing the distribution of inelastic flexural deformations over the height. This affects also the base shear distribution and in particular avoids base shear lockingin once the plastic hinges at the base of the long and the short walls have formed. Furthermore, based on the R-O results, it is recommended describing the moment-rotation relationship of the plastic hinges by a rounded backbone curve, because the shape of this curve also appears to improve the agreement with the benchmark results (Figure 14).

\subsection{Cyclic pushover analysis}

During an earthquake, the structure is subjected to load reversal. When interconnected cantilever wall structures were analysed in past studies, it was found that the peak base shear in the long wall occurs upon load reversal [3]. A cyclic pushover analyses can be used to capture this peak. This section presents the results of different cyclic pushover analyses and shows that the peak shear forces only occur upon load reversal if oversimplifying modelling assumptions are used. When the modelling 
recommendations summarised in Section 5.6 are followed, the shear forces are very similar for the first and second loading branches, and hence, a simple pushover analysis is sufficient to determine the base shear distribution in an interconnected wall system.

Figures 16 and 17 show the base shear deformation relationships obtained from cyclic pushover analysis of the interconnected cantilever wall system for two different modelling approaches in comparison to the SEM results: The first one is the common simple approach, which is based on lumped plasticity elements in conjunction with bilinear hysteresis (Figure 16). The peak shear force of the long wall, which yields first, occurs after load reversal. If shear flexibility is considered, the peak shear force reduces but still occurs after load reversal. When distributed plasticity beam elements are used, the peak shear forces in all loading branches are very similar whether shear flexibility is considered or not (Figure 17). Shear flexibility has, however, a significant influence on the shape of the base shear-top displacement hysteresis. This is a further reason why shear flexibility should be considered when time history analysis is carried out. While the LPBM with the elastic-plastic hysteresis rule can estimate the peak shear forces reasonably well when shear flexibility is included, it cannot capture the cyclic response correctly (Figure 16). When compared to SEM results, the hysteretic cycles are far too wide, hence overestimating the energy absorbed by the system. The DPBM, on the contrary, captures also the shape of the hysteretic curve rather well (Figure 17).

\section{PARAMETRIC ANALYSIS OF CANTILEVER WALL SYSTEMS}

The pushover analyses presented in the previous sections have shown that the base shear in the shorter wall is larger when the walls are interconnected than when they are not. The increase in base shear of the short wall due to compatibility can be estimated by the amplification factor $\Lambda_{2}$ :

$$
\Lambda_{2}=\frac{V_{2, \max }}{M_{2 y} / h_{\text {eff }}}
$$

where $V_{2, \max }$ is the maximum base shear of the short wall (Wall 2) in the interconnected system, $M_{2 y}$ is the yield moment of the short wall and $h_{\text {eff }}$ is the height of the lateral forces resultant representing the horizontal inertia forces. On the other hand, the maximum base shear of the long wall (Wall 1) can be estimated as that of the single wall, that is, $\Lambda_{1}=1$.

A parametric study on interconnected walls with effective wall stiffness ratios $E I_{\text {long }} / E I_{\text {short }}$ up to 23 and effective heights up to seven times the storey height was conducted. The effective wall stiffness are

a)

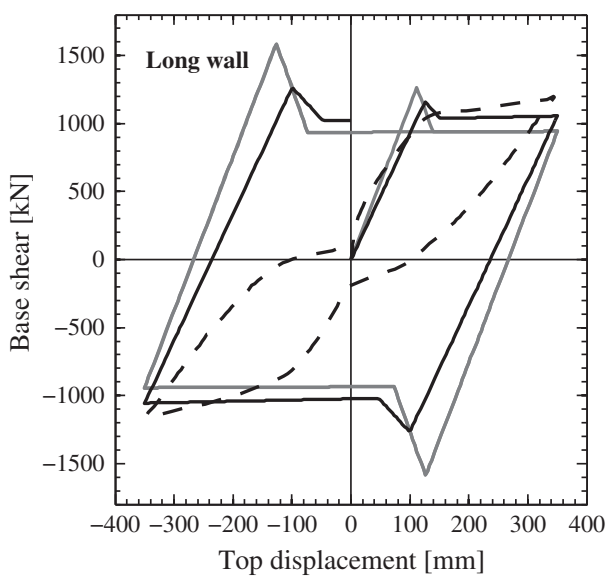

b)

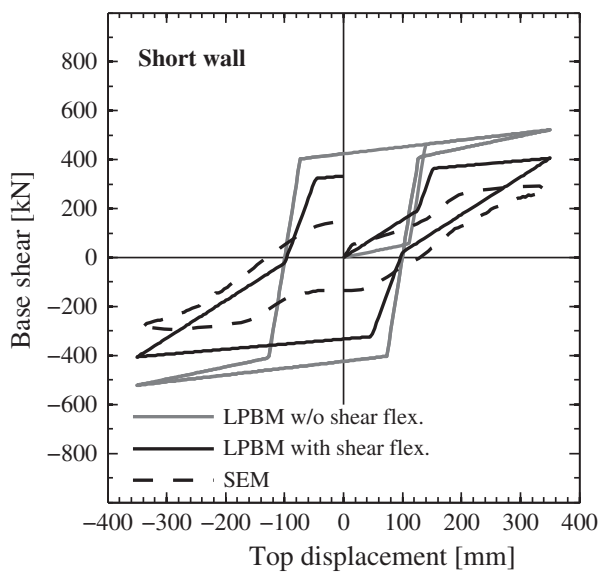

Figure 16. Cyclic pushover analysis for lumped plasticity beam element (LPBM) with bilinear hysteresis (one plastic hinge per wall): effect of shear deformations on force-deformation relationships for the long and short wall of the interconnected wall system. 
a)

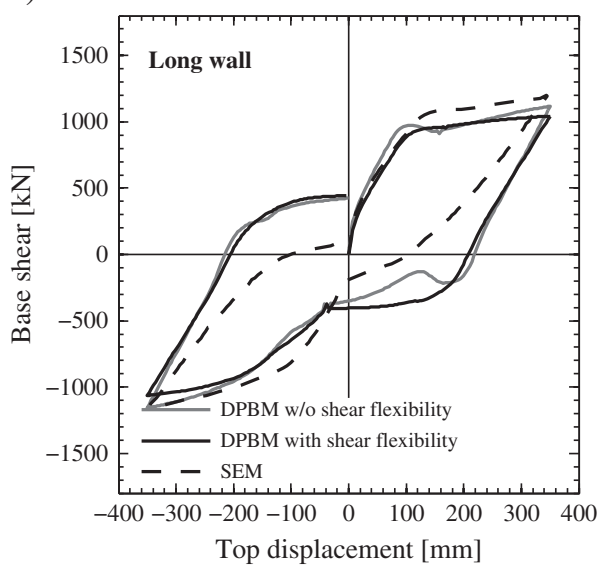

b)

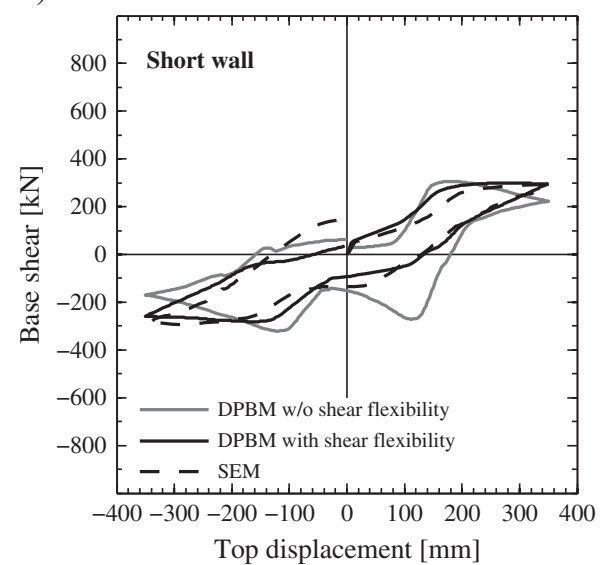

Figure 17. Cyclic pushover analysis for the distributed plasticity beam element (DPBM): effect of shear deformations on force-deformation relationships for the long and short wall of the interconnected wall system.

computed per Equation (8). The effective height is the height of the resultant lateral force (Equation (4)). The cantilever wall systems were analysed following the modelling recommendations outlined in Section 5.5 for models with displacement-based beam elements with fibre sections. The resulting amplification factors $\Lambda_{2}$ are summarised in Figure 18, showing that for the analysed systems amplification factors as large as 2.5 are obtained. Such increase in base shear demand on the short wall should clearly be considered in design. Although design engineers might verify their final design by inelastic analysis of the structure, checking the feasibility of certain design choices may warrant a rough estimate of the base shear amplification before inelastic analyses are performed. Rutenberg [3] developed a model, which was summarised in Section 3.2 that allows deriving an estimate of $\Lambda_{2}$ :

$$
\begin{gathered}
\Lambda_{2}^{*}=\frac{V_{2, \max }}{M_{2 y} / h_{e f f}}=1+\gamma(\beta-1) \\
\gamma=1-\frac{\phi_{y, \text { long }}}{\phi_{y, \text { short }}}
\end{gathered}
$$

a)

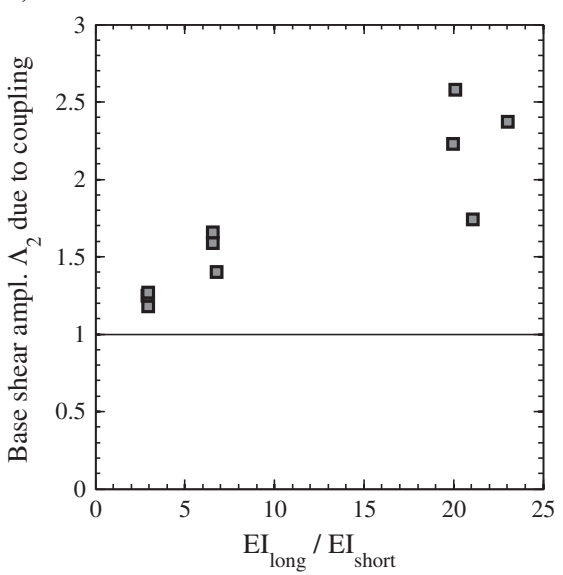

b)

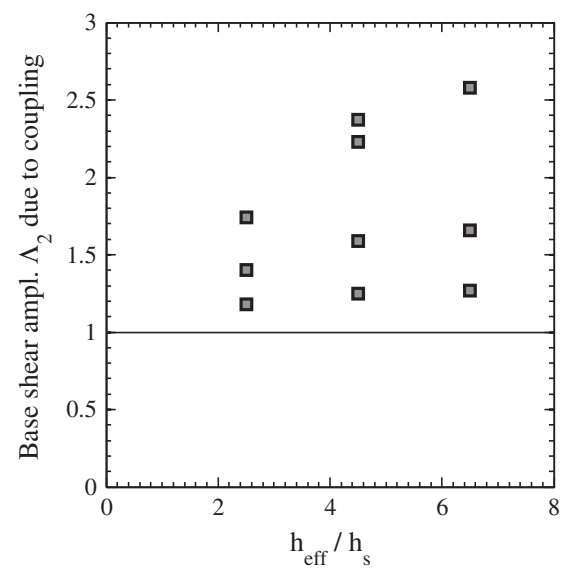

Figure 18. Amplification factor $\Lambda_{2}$ obtained from numerical analyses as (a) function of $E I_{\text {long }} / E I_{\text {short }}$ and (b) as function of $h_{\text {eff }} / h_{s}$. 
a)

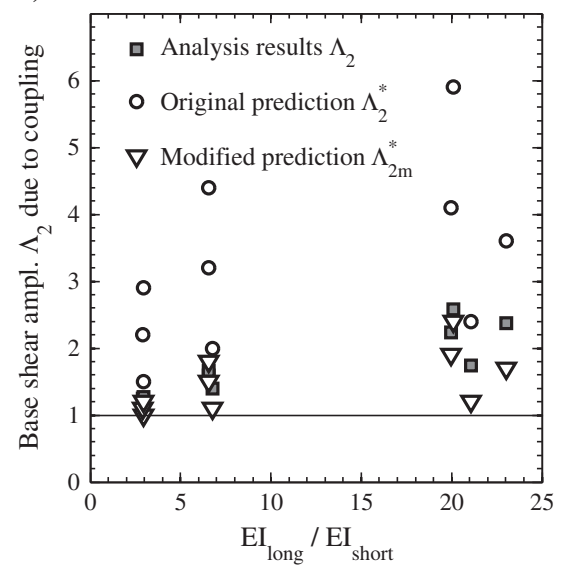

b)

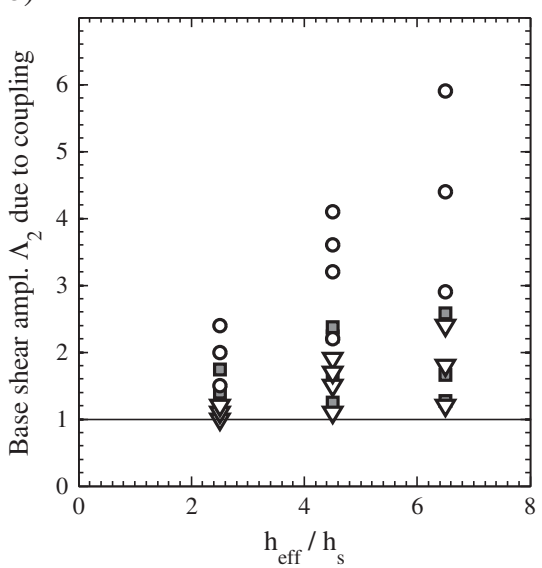

Figure 19. Comparison of predicted $\Lambda_{2}{ }^{*}$ and $\Lambda_{2, m}{ }^{*}$ to $\Lambda_{2}$ from pushover.

$$
\beta=\left(1+(3-\sqrt{3}) \frac{h_{\text {eff }}}{h_{s}} \cdot \frac{E I_{\text {long }}}{E I_{\text {short }}}\right) \frac{E I_{\text {short }}}{E I_{\text {long }}+E I_{\text {short }}}
$$

Figure 19 compares the predicted amplification factors to those obtained from pushover analysis. The results show that this original model yields rather conservative estimates of the amplification factor. This is for the following reasons:

- The model is based on the assumption that the walls undergo only flexural deformations. Pushover analyses have shown, however, that considering shear flexibility reduces the base shear force in the short wall considerably.

- The model is based on the assumption that the walls form idealised hinges at their bases. In an RC wall, the inelasticity will, however, spread over a certain height.

To account for these effects, the original amplification factor is modified empirically as follows:

$$
\begin{gathered}
\Lambda_{2 \mathrm{~m}}^{*}=\frac{V_{2, \max }}{M_{2 y} / h_{\text {eff }}}=\frac{1+\gamma\left(\beta_{m}-1\right)}{0.2\left(\frac{h_{\text {eff }}}{h_{s}}-1\right)+1} \geqslant 1 \\
\beta_{m}=\left(1+(3-\sqrt{3}) \frac{h_{\text {eff }}-h_{s}}{h_{s}} \cdot \frac{E I_{\text {long }}}{E I_{\text {short }}}\right) \frac{E I_{\text {short }}}{E I_{\text {long }}+E I_{\text {short }}}
\end{gathered}
$$

The modified amplification factor is equal to unity when the resultant lateral force acts at the first storey $\left(h_{\text {eff }}=h_{s}\right)$ or when the yield curvatures of the two walls are identical $(\gamma=0$, Equation (13)). Figure 19 shows that the modified amplification factor approximates well the factors found from pushover analysis.

\section{DISCUSSION AND CONCLUSIONS}

Good estimates of shear force demand on structural elements are a necessity in seismic design. If shear demand is underestimated, premature shear failure might lead to an appreciably reduced deformation capacity of the structure. The large base shear forces on the short wall forming part of an interconnected cantilever wall system as evaluated by lumped plasticity beam element models were therefore of concern [3-6]. These shear forces result from enforcing displacement compatibility by the in-plane rigidity of the floor slabs interconnecting the walls. The compatibility forces arose after 
yielding of the long wall when the short wall was still elastic and caused redistribution of the base shear from the long to the short wall. The objective of this paper was to investigate whether the resulting large base shear forces on the short wall were 'real' or whether they were mainly due to simplifying modelling assumptions.

In order to examine the shear forces in cantilever wall systems, an eight-storey 2-walls planar example structure was analysed. The base shear distribution was predicted using two handcalculation methods and two numerical models. For the latter ones, a nonlinear SEM analysed with VecTor 2 was considered to yield benchmark results, and the results of the other models were compared to VecTor2. The comparison showed that the analytical and numerical models based on the lumped plasticity approach overestimated the peak base shear in the short wall. However, considering the two walls as not interconnected underestimated the peak base shear in the short wall.

As the setting up of a SEM requires some expertise, equivalent frame models are often used for the seismic design and assessment of RC cantilever wall systems. Pushover analyses of beam element models showed that the base shear distribution in RC cantilever wall systems is very sensitive to modelling assumptions while the system's response was insensitive. Comparing the results obtained for the beam element models to those for the shell elements showed that realistic shear flexibility of the cracked RC walls must be included in the model if reliable estimates of the base shear distribution are to be obtained. Such an analysis will also yield the shear force distribution over the wall height and show that typically the compatibility forces affect only the bottom quarter of the wall height.

Results of lumped plasticity beam element models might further be improved if additional hinges are introduced over the height of the first storey, their effectiveness depending on their location along height and post-yield stiffness. As already observed, Ramberg-Osgood hysteresis is not considered suitable for modelling RC structures; yet, the R-O pushover results suggest that the use of a rounded hysteresis rule can improve the agreement with the benchmark. Note, however, that while hysteresis rules such as R-O could be suitable for pushover analysis they are less suitable for time history analysis since the hysteretic energy absorption associated with them overestimates the absorption capacity of RC walls.

The design process of wall structures requires estimates of the increase in base shear demand on the short wall accounting for the compatibility forces transferred from the long wall due to interconnection when detailed nonlinear analyses is not performed. A mechanical model suitable for hand-calculations was proposed earlier. As that model neglects the shear flexibility of the walls, it overestimates shear amplification. Based on a limited parameter study, the base shear amplification derived from that model was modified herein by an empirical factor to yield less conservative yet more realistic estimates.

\section{ACKNOWLEDGEMENTS}

The authors would like to thank the two anonymous reviewers for the insightful comments that helped to improve the manuscript. The first author wishes to thank Professors José Restrepo, Nigel Priestley, Michele Calvi and Rui Pinho with whom the question of compatibility forces in interconnected cantilever wall systems was first discussed and studied.

\section{REFERENCES}

1. Paulay T, Priestley MJN. Seismic Design of Reinforced Concrete and Masonry Buildings. John Wiley and Sons, Inc.: New York, 1992.

2. Rutenberg A. Seismic shear forces on RC walls: review and bibliography. Bulletin of Earthquake Engineering 2013; 11:1727-1751.

3. Rutenberg A. The seismic shear of ductile cantilever wall systems in multi-storey structures. Earthquake Engineering and Structural Dynamics 2004; 33:881-896.

4. Rutenberg A, Nsieri E. The seismic shear demand in ductile cantilever all systems and the EC8 provisions. Bulletin of Earthquake Engineering 2006; 4:1-21.

5. Beyer K. Design and analysis of walls coupled by floor diaphragms. MSc Dissertation, Roseschool, Pavia, Italy, 2005.

6. Simonini S. Seismic analysis of RC walls with unequal lengths. MSc Dissertation, University of Bologna, Italy, 2011.

7. Paulay T, Restrepo JI. Displacement and ductility compatibility in buildings with mixed structural systems. Bulletin of the New Zealand National Society for Earthquake Engineering 1998; 11:7-12.

8. CEN. Eurocode 8: design of structures for earthquake resistance, Part 1: general rules, seismic actions and rules for buildings (EN 1998-1:2004). European Committee for Standardisation, Brussels, Belgium, 2004.

9. Priestley MJN, Calvi GM, Kowalsky MJ. Displacement-based seismic design of structures. IUSS Press: Pavia, Italy, 2007. 
10. Wong P, Vecchio FJ. VecTor2 and Formworks Manual. University of Toronto, Department of Civil Engineering: Canada, 2002.

11. Vecchio FJ, Collins MP. The modified compression-field theory for reinforced concrete elements subjected to shear. ACI Journal 1986; 83(2):219-231.

12. Vecchio FJ, Lai D, Whim W, Ng J. Disturbed stress field model for reinforced concrete: validation. Journal of Structural Engineering 2001; 127(4):350-358.

13. Mander JB, Priestley MJN, Park R. Theoretical stress-strain model for confined concrete. Journal of Structural Engineering 1998; 114(8):1804-1826.

14. Beyer K, Dazio A, Priestley MJN. Inelastic wide-column models for U-shaped reinforced concrete walls. Journal of Earthquake Engineering 2008; 12(Suppl. 1):1-33.

15. Dolšek M, Fajfar P. Mathematical modelling of an infilled RC frame structure. Earthquake Engineering and Structural Dynamics 2002; 31:1215-1230.

16. SeismoSoft. Seismostruct - A computer program for static and dynamic non-linear analysis of framed structures. Version 5.0.5. Seismosoft srl, Pavia, Italy, 2011.

17. Bathe KJ. Finite Element Procedures. Prentice Hall: New Jersey, 1996.

18. Yazgan U, Dazio A. Simulating maximum and residual displacements of RC structures: I. Accuracy. Earthquake Spectra 2011; 27:1187-1202.

19. Beyer K, Dazio A, Priestley MJN. Shear deformations of slender reinforced concrete walls under seismic loading. ACI Structural Journal 2011; 108(2):167-177.

20. Collins MP. Mitchell Prestressed Concrete Structures. Response Publication: Toronto, 1997.

21. Spacone E, Filippou FC, Taucer FF. Fibre beamcolumn model for nonlinear analysis of R/C frames. I: Formulation. Earthquake Engineering and Structural Dynamics 1996; 25:711-725.

22. Otani S. Hysteretic models of reinforced concrete for earthquake response analysis. Journal of the Faculty of Engineering, University of Tokyo 1981; XXXVI(2):1-24. 